\title{
Nanomaterials in the European chemicals legislation - methodological challenges for registration and environmental safety assessment
}

Nielsen, Maria Bille; Baun, Anders; Mackevica, Aiga; Thit, Amalie; Odnevall Wallinder, Inger; Gallego, Julián Álberto; Clausen, Lauge Peter Westergaard; Rissler, Jenny; Skjolding, Lars Michael; Castro Nilsson, Alejandra

Total number of authors:

12

Published in:

Environmental Science: Nano

Link to article, DOI:

10.1039/DOEN01123A

Publication date:

2021

Document Version

Peer reviewed version

Link back to DTU Orbit

Citation (APA):

Nielsen, M. B., Baun, A., Mackevica, A., Thit, A., Odnevall Wallinder, I., Gallego, J. A., Clausen, L. P. W. Rissler, J., Skjolding, L. M., Castro Nilsson, A., Cedervall, T., \& Hansen, S. F. (2021). Nanomaterials in the European chemicals legislation - methodological challenges for registration and environmental safety assessment. Environmental Science: Nano, 8, 731-747. https://doi.org/10.1039/D0EN01123A

\section{General rights}

Copyright and moral rights for the publications made accessible in the public portal are retained by the authors and/or other copyright owners and it is a condition of accessing publications that users recognise and abide by the legal requirements associated with these rights.

- Users may download and print one copy of any publication from the public portal for the purpose of private study or research.

- You may not further distribute the material or use it for any profit-making activity or commercial gain

- You may freely distribute the URL identifying the publication in the public portal 


\title{
1 Nanomaterials in the European chemicals legislation \\ 2 - methodological challenges for registration and 3 environmental safety assessment
}

4 Maria Bille Nielsen ${ }^{1 *}$, Anders Baun ${ }^{1}$, Aiga Mackevica ${ }^{1}$, Amalie Thit ${ }^{2}$, Inger Odnevall Wallinder ${ }^{3}$,

5 Julián Alberto Gallego ${ }^{4}$, Lauge Peter Westergaard Clausen ${ }^{1}$, Jenny Rissler ${ }^{5}$, Lars Skjolding ${ }^{1}$,

6 Alejandra Castro Nilsson ${ }^{6}$, Tommy Cedervall' ${ }^{7}$, Steffen Foss Hansen ${ }^{1}$

\begin{abstract}
In the European Union the Annexes of its chemical legislation (REACH) were revised and now clarifies the technical data requirements for nanomaterials (NMs). These new provisions, effective from January 1, 2020, introduce requirements for manufacturers, importers and downstream users regarding registration and safety assessment of NMs. This study aims to assess the availability and suitability of methods needed to comply with the new regulatory provisions on NMs for physicochemical characterisation and environmental fate and effects. The scientific literature and relevant test guideline frameworks were reviewed to identify applicable methods. These were subsequently evaluated and categorised as either: 'internationally accepted test guideline or standard (TGS)', 'internationally accepted test guideline or standard under development (TGSUD)', 'established as standard methods in scientific literature (SCI)', 'other methods and/or more research needed $(\mathrm{O})$ ' or 'no method $(\mathrm{N})$ '. We find that $80 \%$ of the information requirements and a bit more than $40 \%$ of the waiving criteria in the new REACH Annexes are supported by methods that are available as TGS, TGSUD or SCI. Most of the relevant methods in the scientific literature are included in recent OECD guidance documents or ECHA guidance. We recommend that a targeted effort is made to develop protocols and guidelines for methods to determine NM adsorption/desorption, degradation, exposure scenarios and ability to cross biological membranes. Here methods to fulfil the information requirements and waiving criteria are currently lacking. Furthermore, we recommend that increasing attention is directed towards regulatory reliability and relevance of the information that is submitted by the registrants.
\end{abstract}

\section{Introduction}

Widespread use of nanomaterials (NMs) and their inevitable release to the environment have led to concerns for the environment and human health. NMs possess unique properties, afforded by their high surface area-to-volume ratio ${ }^{1}$ and by engineering the material characteristics at the nanoscale such as size, shape and surface coating to fit a specific purpose. ${ }^{2}$ This can change properties such as reactivity, surface composition, and dispersion stability, causing the nanomaterials to behave differently from their macroscale material counterparts. ${ }^{1-3}$

Several health and environmental legislations exist in Europe with the purpose, among others, to secure safe use and production of chemicals and consumer products. The need for considering

\footnotetext{
${ }^{1}$ Department of Environmental Engineering, Technical University of Denmark, 2800 Kgs. Lyngby, Denmark

* Corresponding author: mabini@env.dtu.dk

${ }^{2}$ Department of Science and Environment, Roskilde University, 4000 Roskilde, Denmark

${ }^{3}$ KTH Royal Institute of Technology, Department Chemistry, Division Surface and Corrosion Science, 11428 Stockholm, Sweden

${ }^{4}$ Department of Marine Sciences, University of Gothenburg, Kristineberg marine research station, 45178 Fiskebäckskil, Sweden

${ }^{5}$ Department of Design Sciences, Lund University, Box 118, 22100 Lund, Sweden \& Department of Material and Surface Design, RISE Research Institutes of Sweden, SE-223 60 Lund, Sweden
}

${ }^{6}$ SOLVE Research and Consultancy AB, Medicon village, SE-22381 Lund, Sweden

${ }^{7}$ Department of Biochemistry and Structural Biology, Lund University, Box 117, 221 00, Lund, Sweden 
nano-specific properties in these regulations has received growing attention and implementation of regulation with nano-specific provisions has increased substantially in recent years. In April 2018, the European Union adopted Annex revisions ${ }^{4}$ in its chemical legislation called Registration, Evaluation, Authorisation and Restriction of Chemicals (REACH). ${ }^{5} \mathrm{REACH}$ applies to NMs and operates with tonnage-triggered data requirements meaning that the higher the annual production volume per producer, the more chemical safety information and data the registration has to provide. The tonnage-triggered data requirements are laid down in the annexes with a lowest tonnage trigger of one tonne per year. The total tonnage of a substance, including a NM, placed on the market is the sum of the individual tonnages per registrant. With the revisions of REACH, a comprehensive set of specific requirements for NMs was introduced. The new requirements, which have been in force since January 1, 2020, apply to manufacturers, importers and downstream users of NMs and establish specific rules regarding registration and chemical safety assessment (referred to as 'safety assessment' hereafter) of NMs. A NM must be registered in order to be placed on the market if the total yearly amount of the substance, including both NMs and potential bulk form, is above one tonne. ${ }^{4,6}$ The requirement to complete a safety assessment is triggered for substances in quantities of more than 10 tonnes. ${ }^{5}$

In order to comply with the new registration and safety assessment requirements, a comprehensive set of information on the NMs must be provided. This information includes among others information on physical and chemical properties of NMs (such as size, morphology and dissolution rates), environmental fate as well as their toxic potency.

At the initial deadline (January 1, 2020), the European Chemicals Agency (ECHA) had only received 50 unique registrations covering 16 substances. ${ }^{7}$ By February 2020, ECHA had merely received 95 unique registration updates covering 36 chemicals in nanoform corresponding to $10 \%$ of their expected number of registrations. Updates were received on among other titanium dioxide, multi-walled carbon nanotubes, cerium oxide and carbon black, but information on some 270 substances was missing when compared to what ECHA had foreseen based on national inventories and an EU catalogue of NMs in cosmetics. ${ }^{8}$ It has furthermore been reported that almost half of the submissions that were received originally failed the completeness check due to incomplete justifications for registering separate nanoforms as sets of similar nanoforms or for waiving certain information requirements. ${ }^{8}$ This has since then been improved for all, but two registrations after the companies were given a four months deadline. 9 Seven months after the original deadline for submissions had ECHA received 136 unique registration updates covering 52 chemicals. This is estimated to correspond to one-sixth of substances containing nanoforms. ${ }^{9}$ There is currently no public information available on how many of the registrations are for substances produced in volumes of 100 tonnes or above per year. Interestingly, ECHA has not received any testing proposals for the Annex IX and X endpoints that are included in the REACH Annex revisions, including endpoints such as bioaccumulation in aquatic species and effects on terrestrial organisms. The tonnage triggers for the information requirements in Annex IX and $X$ are 100 and 1000 tonnes or more, respectively. According to ECHA, it remains to be seen if registrants are currently mainly focusing on their specific nanoform characterisation and not (yet) on the hazard information. ${ }^{8}$

Application of conventional methods to test these parameters is often challenged by the specific properties of NMs and their non-equilibrium system-dependent behaviours. This has imposed the need for new or modified methods..$^{10}$

There is currently no full overview of the availability and suitability of methods needed to fulfil the new nano-specific requirements in REACH. This places NM producers and users in a challenging situation as articulated by the European Chemical Industry Council (Cefic). Cefic is the branch organisation of the European chemical industry and consists of a network of 600 companies across 90 different sectors. In a recent letter, ${ }^{11}$ Cefic argues that there is a lack of fully developed test methods to fulfil the requirements. Together with the European non-ferrous metals association, Eurometaux, Cefic also pointed to concerns about business confidentially and delays in the provisions of necessary IT tools and guidance provided by ECHA. As a consequence, Cefic and Eurometaux call for more time and flexibility for registrants to perform updates. They suggested to waive data generation for information requirements without associated test methods, or standards, until these become 
available and furthermore enforcement could direct Cefic to contact companies that have not yet updated their existing dossiers. ${ }^{12}$ EU Member States have also pointed at the absence of available test methods for certain endpoints as well as lack of laboratory capacity and short timeframe allowed for compliance. On the other hand, representatives from two NGOs, the European Environment Bureau and Center for International Environmental Law, have called for ECHA to take a tougher stand and deny the NM market access unless a minimum set of data is submitted. They argue that the lack of guidance does not help to explain the lack of registrations..$^{12}$

ECHA has acknowledged the challenges that industry and registrants face to generate the necessary data and the length of time needed to revise the available OECD test guidelines (TGs), on which the agency's own guidance relies. ${ }^{7}$ ECHA has publicly stated that it has adopted a temporary approach for endpoints where an internationally agreed test method does not exist and states that the lack of certain test methods should not be a hurdle in the registration process. It has also been reported that ECHA has postponed the publication of updated guidance on characterisation of human health and environmental endpoints to ensure that internationally recognised test methods are available. ${ }^{7}$ Updates of EHCA's existing guidance made for NM substance identification and chemical safety assessment, published in 2017,6,13 have been postponed and are expected in August 2021 and September 2022 for human health endpoints and environmental endpoints, respectively. The stakeholder consultation is planned for the first quarter of 2021 for human endpoints and for the second quarter of 2022 for environmental endpoints. ${ }^{7}$ Until then, the European Union Observatory for NM (EUON) hosted by ECHA has prepared an updated list of test guidelines and ongoing test guideline developments relevant for meeting the information requirements of the REACH Annexes. ${ }^{14}$

This study aims to assess the degree of availability and suitability of methods needed to comply with the new regulatory provisions on NMs for physico-chemical characterisation and environmental fate and effect assessment. The latter is especially interesting to study as updates to the official guidance have been called for very recently by experts from the German Environment Agency (UBA) and the Dutch National Institute for Public Health and the Environment (RIVM). ${ }^{15,16}$ UBA and RIVM argued that significant uncertainties will remain as long as standardised TGs, guidance and monitoring data are lacking and call for the use of an additional safety factor to account for nanorelated uncertainties. ${ }^{15}$ Many information requirements include criteria that either impose additional requirements or waive requirements, in case they are fulfilled. The availability of methods needed to evaluate these criteria will also be assessed. Based on our analysis of methodological gaps, recommendations will be provided on how to prioritise future efforts to assist NM registrants meet their new legal obligations.

\section{Materials and Methods}

\subsection{Literature review}

A literature review was conducted to identify available methods applicable for gathering the information according to data requirements for registration of nanoforms under REACH. The same procedure was carried out for the criteria included in the information requirements (criteria to impose additional requirements or waiving criteria). Web of Science was used to screen for methods in published literature. For every synonym of nanomaterials identified, searches were conducted with keywords related to methods (i.e. methods, tools, assessments, measurements and evaluations) combined with keywords related to the individual information requirements and waiving criteria (dissolution, biodegradation and particle size distribution etc.). Backward and forward reference searches were conducted for relevant references identified. Targeted searches for methods established in TGs, standards or other type of guidance were carried out within the frameworks of Organisation for Economic Co-operation and Development (OECD), the International Organization for Standardization (ISO) and European Chemicals Agency (ECHA) and their respective databases and catalogues.

\subsection{Categorisation of methods}


All identified methods relevant to information and data requirements for registration of nanoforms under REACH were evaluated. Each method was assigned to one of the following categories: Internationally accepted test guideline or standard (TGS), Internationally accepted test guideline or standard under development (TGSUD), Established as standard method in the scientific literature (SCI), Other method and/or more research needed $(\mathrm{O})$ or No method $(\mathrm{N})$. For information and data requirements where no methods were identified, the method category No method $(\mathrm{N})$ was applied. Methods established as TGS (e.g. an OECD TG or ISO standard)) are considered the most important from a regulatory perspective as these are the fundament of current risk assessment procedures and of ECHA's guidance on chemical safety assessment. According to EUON, TGs are needed to support the regulatory testing of nanomaterials and should assist to ensure that tests are done uniformly across different labs and are delivering relevant and reliable data. ${ }^{14}$ OECD develops both OECD TGs and OECD GDs, which are different types of documents for regulatory testing of chemicals. The OECD TGs are internationally recognised test methods and their results fall under OECD's system of Mutual Acceptance of Data (MAD). OECD GDs are not part of the MAD system. As far as possible the OECD test guideline programme develops TGs and GDs may be developed if e.g. particular groups of materials need additional explanation. In 2006, OECD established a Working Party on Manufactured Nanomaterials (WPMN), which aims at discussing regulatory aspects regarding nano-safety and assessing whether existing TGs can be applied to NMs, and exploring the need for new TGs that would be nano-specific. The development of new OECD TGs is built on knowledge from available research and regulatory requirements. ${ }^{17}$ These TGs describe how to test and report on potential effects of chemicals, including among others, their physical-chemical properties and environmental fate and behavior. ISO develops international standards within a wide range of areas, including chemical technology and environmental management, some of which overlap with the OECD TGs e.g. on ecotoxicity of chemicals. ISO standards are developed by technical committees (TCs) consisting of groups of experts representing the relevant sectors. ${ }^{18}$ For nanomaterials the relevant committee is ISO/TC 229 on Nanotechnologies. In addition to international standards, ISO develops technical specifications (TSs) and technical reports (TRs) and these do not account for TGs in this analysis. A TS entails work that is still under development and can be provided for immediate use and/or a tool to obtain feedback until it may eventually be republished as an international standard. The information provided in a TR can e.g. include data obtained from surveys or information of the perceived "state of the art" in an area. ${ }^{19}$ ECHA manages the technical and administrative aspects of REACH and has developed a range of guidance to assist manufacturers and importers of chemicals in complying with REACH. Most of this guidance refer to OECD TGs and ISO standards, but when not available also on the scientific literature.6,13 The method category 'Established as standard method in the scientific literature' entails methods that are not standardised methods in the sense that OECD TGs and/or ISO standards exist, but which often are referred to and used in the scientific literature to an extent where it is considered a minimum reporting requirement for scientific publications. ${ }^{20,21}$ Methods that also belong to this method category are those for which OECD GDs or ISO TRs or TSs exist. Methods that are under development which are only available to a limited number of pioneering research groups or that have only been discussed theoretically in the scientific literature fall into the category 'Other method and/or more research needed'. Only one method category are assigned to each information requirement or criteria. In situations where more than one method are available for one information requirement or criteria, the highest ranked method category applies. The method categories are ranked highest to lowest: TG, TGUD, S, O and N. Methods were evaluated according to their availability and suitability. For evaluating availability, criteria included consideration of whether methods are public accessible/free of charge as well as whether certain technology is needed for its application and how available this technology is. Suitability was assessed by considering if the identified methods are applicable to nanomaterials or whether noteworthy limitations exist. 
191 For all the information requirements listed in the REACH Annexes, ${ }^{4}$ we gathered information about 192 the availablity of metods, protocols and guidelines from OECD, ISO and ECHA and their respective 193 databases and catalogues as well as the scientific literature. Table 1 provides an example of 194 information compiled for the first information requirement, namely 7.7 Solubility (and dissolution 195 rate). A full overview of all information collected for each information requirement is given in 196 Electronic Supplementary Material 1 and 2. 
197 Table 1. Example of information collected on the availablity of metods, protocols and guidelines for the information requirement 7.7 Solubility (and dissolution rate) and its waiving criteria and the highest-ranked category of identified methods needed to acquire/fulfill the information requirement and its waiving criteria set by the European chemicals legislation REACH for nanomaterials (NMs). Details for the full overview is given in Electronic Supplementary Material 1. TGS: Internationally accepted test guideline or standard; TGSUD: Internationally accepted test guideline under development; SCI: Established as standard method in scientific literature; O: Other method and/or more research needed; N: No method identified. The method categories are ranked highest to lowest: TGS, TGSUD, SCI, O and N. Other abbreviations: TR: technical report; GD: guidance document; Organisation for Economic Co-operation and Development (OECD); ISO:

\section{Information requirement Waiving criteria Methods, protocols and guidance}

\subsection{Solubility (and}

dissolution rate) environment ongoing. ${ }^{22}$
- OECD WNT Project 3.10: New TG on dissolution rate of NMs in aquatic

- OECD WNT Project 1.5: GD on determination of solubility and dissolution rate of NMs in water and relevant synthetic biological media ongoing for new guidance document/test guideline. ${ }^{22}$

- GD 318 for the testing of dissolution and dispersion stability of NMs, and the use of the data for further environmental testing and assessment. ${ }^{23}$ The GD lists the following methods:

1. Batch test using Centrifugal ultrafiltration (not recommended ultracentrifugation or dialysis)

2. Dynamic testing of dissolution rates based on Koltermann-Jülly et al. ${ }^{24}$

- Partially covered in ECHA Guidance. ${ }^{13,14}$

- OECD TG 10525: not adapted to NMs specifically

- ISO/TR 1905726: adapted to NMs

- OECD GD 29 on Transformation/ Dissolution of Metals and Metal Compounds in Aqueous Media ${ }^{27}$ is applicable for some NMs. E.g., Wasmuth et al. ${ }^{28}$ applied it successfully to silver NMs.

- Multiparameter matrix methods may be used to study dissolution and solubility. E.g., Xiao et al..$^{29}$ performed a multifactorial design for the water chemistry (based on OECD-TG-318 matrix of parameters: natural organic matter, ionic strength and $\mathrm{pH}$ ).

- Study of dissolution of metal NMs environmental (freshwater) conditions. ${ }^{30,31}$

\section{Highest method} category TGSUD 
(7.7.)

Hydrolytically

stability or

readily

oxidisable
- OECD Project 3.10 (New TG on dissolution rates of NMs in aquatic environments) includes a screening test to assess whether they fall into the category of rapidly dissolving NMs. ${ }^{22}$

$$
\text { ** }
$$

${ }^{* *}$ Hydrolytically NMs are in this context considered unstable or readily oxidisable or rapidly dissolving (half-life less than $12 \mathrm{~h}$ ). 


\subsection{Information requirements}

In total, there are 20 additional, nano-specific information requirements for which methods are needed in order to register substances that are (also) nanoforms in REACH. All the identified methods were categorised as described above. Figure 1 shows the distribution of methods categories for methods to acquire/fulfill information requirements of $\mathrm{REACH}$ regulation on NMs. Internationally accepted TGs or standards are available (see Figure 1A) for 15\% (3 out of 20) of the information requirements. This is the case for information requirements 'Further information on physicochemical properties', 'Simulation testing on ultimate degradation in surface water' and 'Hydrolysis as function of $\mathrm{pH}^{\prime}$, for which OECD TGs exist.

A. Information requirements

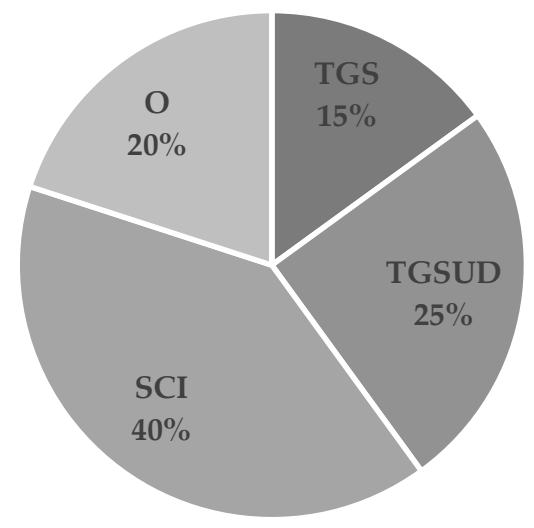

B. Waiving criteria

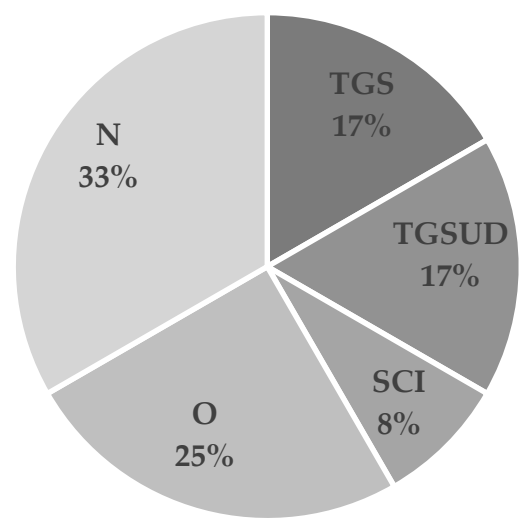

Figure 1. Distribution of method categories for methods, protocols and guidance identified to acquire/fulfill information requirements (A) and to assess waiving criteria for information requirements (B) in the REACH Annexes on nanomaterials. Method categories represents the highest-ranked method for each information requirement and waiving criteria, where the ranking from highest to lowest are: TGS, TGSUD, SCI, O and N. TGS: Internationally accepted test guideline; TGSUD: Internationally accepted test guideline under development; SCI: Established as standard method in scientific literature; O: Other method and/or more research needed; N: No method identified.

For $25 \%$ (5 out of 20) of the information requirements, we identified methods that are under development into TGs or standards. This was especially the case for methods related to solubility (and dissolution rate) and dustiness, but also aspects of particle characterisation such as particle size distribution, shape and specific surface area (see Table 2). Table 2 provides a summary on information gathered in the Electronic Supplementary Materials 1 and compiles methods, protocols and guidance that we have been able to identify for each information requirements together with our categorisation of the best-ranked identified method for each requirement.

ECHA directly cites or considers the state-of-the-art within the scientific literature which are related to the new information requirements for NMs. Our literature review shows that $40 \%$ (8 out of 20 information requirements) include modified standard methods or advices to best practice that are available in the scientific literature or in OECD GDs, ECHA guidance or TRs/TS's by ISO. These include methods related to growth inhibition studies on aquatic plants, short-term toxicity testing on fish and invertebrates, and activated sludge respiration inhibition testing, for which methods are presented in OECD GD 317,32 as well as methods to assess bioaccumulation in aquatic species and effects on terrestrial organisms. Included in this category (S) is also the information requirement related to description of surface functionalisation or treatment, for which e.g. ECHA guidance ${ }^{6}$ exists, and characterisation of particle aggregation and agglomeration, for which certain imaging methods are established (see Table 2).

Four out of the 20 information requirements fall under the method category 'Other method and/or more research is needed $(\mathrm{O})^{\prime}$. These are e.g. methods related to assessing adsorption/desorption and the partition coefficient n-octanol/water (see Table 2), for which ECHA 
244 has announced that methodological guidance is partially covered by guidance released on NM 245 substance identification and chemical safety assessment.6,13 Partition coefficient n-octanol/water is not 246 considered applicable for particulate, insoluble NMs. ${ }^{33}$ In the regulation it is stated that where the 247 partition coefficient n-octanol/water is not applicable for a NM, dispersion stability shall be 248 considered instead. For this, OECD TG $318^{34}$ can be used. Another information requirement in the 249 method category ‘Other method and/or more research is needed $(\mathrm{O})^{\prime}$ ' is '9.2 Degradation'. The OECD 250 Working Group of the National Coordinators for the Test Guidelines Programme (WNT) project 3.16 251 is working on a GD addressing abiotic transformations of NMs in environmental media. ${ }^{22}$ ECHA 252 states that the guidance is likely to be available in 2023 or 2024 and that "It may be possible to conduct 253 a qualitative assessment in the meantime". ${ }^{14}$ 
Table 2. The 20 additional, nano-specific information requirements for registration of nanomaterials (NMs) in the European chemicals legiaslation (REACH) ${ }^{4}$ and categories of identified highest-ranked method needed to acquire/fulfill the information requirements. TGS: Internationally accepted test guideline or standard; TGSUD: Internationally accepted test guideline or standard under development; SCI: Established as standard method in scientific literature; O: Other method and/or more research needed; N: No method identified. The method categories are ranked highest to lowest: TGS, TGSUD, SCI, O and N. Other abbreviations: TR: technical report; TS: technical report; GD: guidance document; Organisation for Economic Co-operation and Development (OECD); ISO: International Organization for Standardization; ECHA: the European Chemicals Agency; WNT: Working Group of the National Coordinators for the Test Guidelines Programme. Roman numerals in parentheses and italics refer to the REACH annex that an information requirement belong to (VII = Annex VII/7, etc.).

\begin{tabular}{ll}
\hline Information requirement & $\begin{array}{l}\text { Highest method } \\
\text { category }\end{array}$ \\
\hline
\end{tabular}

7.7 Solubility (and dissolution rate) (VII)

7.8 Partition coefficient n-octanol/ water (VII)

7.14bis Dustiness (VII)

9.1.1 Short-term toxicity testing on invertebrates (VII)

9.1.2 Growth inhibition study aquatic plants (VII)

7.14ter Further information on physico-chemical properties (VIII)

9.1.3 Short-term toxicity testing on fish (VIII)

9.1.4 Activated sludge respiration inhibition testing (VIII)

9.2 Degradation (VIII)

9.2.2.1 Hydrolysis as function of $\mathrm{pH}$ (VIII)

9.3.1 Adsorption/desorption screening (VIII)

TGSUD

$\mathrm{O}$

TGSUD

$\mathrm{SCI}^{*}$

$\mathrm{SCI}^{*}$

TGS

$\mathrm{SCI}^{*}$

$\mathrm{SCI}^{*}$

TGS

$\mathrm{O}^{*}$

\section{Methods, protocols and guidance identified}

OECD WNT Project 3.10: TG under development ${ }^{22}$; OECD WNT Project 1.5: GD under development ${ }^{22}$; OECD GD 31823; ECHA Guidance R7.1a and R7.1b appendices ${ }^{* *} 13$.

OECD GD 2927: applicable for some NMs; Multiparameter matrix methodse.g. 29,35; Dissolution study of metal NMs environmental (freshwater) conditions. ${ }^{30,31}$

ECHA Guidance ${ }^{* *} \cdot 13,14$

OECD WNT Project 1.8: TG under development 22 ; Rotating drum method, continuous drop method and small rotating drum method, ${ }^{33,36}$ for which British standards exist: EN 15051-1, ${ }^{37}$ 15051-238 and EN 15051-3. ${ }^{39}$

ISO/TS 20787:201740; OECD GD 317.32

OECD GD 317.32

OECD decision tree ${ }^{14}$; OECD framework on physical chemical characterisation ${ }^{14}$.

OECD WNT Project 1.7: TG under development ${ }^{22}$; ISO/TR 11360:2010.14,41

OECD GD 317.32

OECD GD 317.32

OECD WNT 3.16 Project: GD under development. ${ }^{22}$ Qualitative assessment may be possible

in the meantime. ${ }^{14}$

OECD TG $318 .{ }^{34}$

ECHA Guidance $2017^{* *} 13,14$; Dye staining to measure hydrophobicity of NMs in aquatic

environments ${ }^{42}$ 
9.2.1.2 Simulation testing on ultimate degradation in surface water (IX)

9.3.2 Bioaccumulation in aquatic species, preferably fish (IX)

9.3.3 Further information on adsorption desorption depending on the results of the study required in Annex VIII (IX)

9.4 Effects on terrestrial organisms (IX)

2.4.2 Number based particle size distribution with indication of the number fraction of constituent particles in the size range within 1 $\mathrm{nm}-100 \mathrm{~nm}$. (VI)

2.4.3 Description of surface functionalisation or treatment and identification of each agent including IUPAC name and CAS or EC number. (VI)

2.4.4 Shape, aspect ratio and other morphological characterisation: crystallinity, information on assembly structure (VI)

2.4.5 Surface area (specific surface area by volume, specific surface area by mass or both) (VI)

5.2.3 Characterisation the particle aggregation and the agglomeration $(I)$

\section{OECD TG $318 .^{34}$}

ICP-MS or AAS for analysis of NMs in dissolved tissue of aquatic organismse.g. 43-45; In vivo and in vitro methods for acellular dissolution in physiological fluids ${ }^{\text {e.g. }}$. 36 ; OECD WNT Project 3.12: GD under development. ${ }^{22}$

ECHA Guidance ${ }^{* * 13,14}$; Dye staining to measure hydrophobicity of NMs in aquatic environments.42

OECD GD $317^{32}$ may be updated for terrestrial organisms ${ }^{14}$; Equilibrium partitioning method may be applied, if scientifically justified ${ }^{4}$; Proposal on OECD TG $312^{46}$ as alternative to equilibrium partitioning method ${ }^{47,48,13}$; Draft OECD GD on testing nanomaterial behaviour in soils using OECD TG 312 under development ${ }^{14}$; OECD TG $303 \mathrm{~A}^{49}$ also proposed as an alternative approach to predict sorption of NMs.

OECD WNT project 1.4: TG under development ${ }^{22}$; ISO/TS 19590:201750; ISO 22412:201751 applies, with certain restrictions ${ }^{33}$; ISO/TS 21362:2018 ${ }^{52}$; Imaging methods, e.g. electron microscopy ${ }^{53}$; Nanoparticle Tracking Analysis (NTA). ${ }^{54}$

ECHA Guidance, ${ }^{6}$ including analytical techniques (e.g. IR, NMR, TGA, ICP-MS, XRF, XPS, EDX, GC-MS, MALDI-TOF, etc.), NANoREG ${ }^{55}$ and ISO TR 14187:2011.56 Revised version: ISO/TR 14187:2020.57

OECD WNT Project 1.4: TG under development ${ }^{22}$; Protocols from research projects and/or standard methods and/or scientific literature available for determination of crystallinity/assembly structure ${ }^{14}$; Electron microscopy (EM) for determination of shape..$^{33}$ OECD WNT Project 1.3: TG under development ${ }^{22}$; ISO/TR 14187:2011 ${ }^{56,57}$ provides some input to relevant information; ISO 9277:201058 applies, with certain restrictions; Determination of the specific surface area of solids by gas adsorption - BET method, with restrictions. ${ }^{33}$

Certain imaging methods, such as electron microscopy ${ }^{53,59}$; Electron microscopy image and transmission electron topography60,61; Draft OECD TG on Agglomeration Behaviour of 
Nanomaterials in Different aquatic Media ${ }^{62}$; Development of a new OECD TG or GD on

determination of aggregation/agglomeration status of NMs is under consideration ${ }^{33}$; Electron

microscopy image and transmission electron topography image. ${ }^{60,61,63}$

$261{ }^{*}$ Method available through ECHA guidance, OECD GDs or ISO TSs/TRs

$262{ }^{* *}$ Information requirement only partially covered by ECHA Guidance. ${ }^{11}$ 
A number of waiving criteria are listed for many of the new nano-specific information requirements listed in the REACH Annexes. ${ }^{4}$ This means that if these criteria are fulfilled for a given information requirement, then the registrant does not have to provide information on this given endpoint. Figure 1B shows the distribution of methods categories for methods needed to assess the waiving criteria.

Our study shows that 12 different waiving criteria are contained in the REACH information requirements for NMs. $17 \%$ (2 out of 12 ) of the waiving criteria were supported by methods in the form of internationally accepted TGs or standards, including methods related to biodegradability and decomposition of the NM (see Table 3). Table 3 summarises the collected information (see Electronic Supplementary Material 1) and includes methods, protocols and guidance that we have been able to identify for each waiving criterion and our categorisation of the best-ranked identified method for assessing each criterion. For another $17 \%$ of the waiving criteria, methods in the form of internationally accepted TGs or standards are currently under development. This applies to methods to inform waiving criteria on solubility and hydrolytically stability/readily oxidisable.

For one waiving criterion, i.e. 'The substance has low potential for bioaccumulation (for instance a $\log \mathrm{K}_{\mathrm{ow}} \leq 3^{\prime}$ ), the method category SCI was assigned. The methods identified in the scientific literature to assess the criterion include ICP-MS or AAS for analysis of NMs in dissolved tissue of aquatic organisms. e.g. 43-45

Other methods/more research are needed for $25 \%$ of the waiving criteria ( 3 out of 12 ). That is e.g. the criterion describing that the information requirement can be waived for inorganic NMs. The criterion related to the likelihood/potential of the substance to cross biological membranes also falls into this category $(\mathrm{O})$. No methods were identified that can sufficiently assess such likelihoods/potentials. However, a list of methods to partly help inform this criterion were gathered (see Table 3).

No methods were identified that can support whether the criteria can be waived for a third (4 out of 12) of the waiving criteria. This was especially the case for the criteria that rely on an assessment of specific exposure scenarios of a NM of concern. Examples of this kind of waiving criteria include 'exposure to granular form of the substance during its life-cycle can be excluded' and 'direct and indirect exposure of the aquatic compartment is unlikely'.

Certain information requirements are linked to criteria that can impose additional information requirements to the substance of concern. Table 4 provides an overview of these criteria and requirements and the identified methods needed to evaluate/fulfill them. 
297 Table 3. Waiving criteria for information requirements for registration of nanomaterials (NMs) in the European chemicals legislation (REACH) and category of identified highest-ranked method needed to assess if waiving criteria are triggered. TGS: Internationally accpted test guideline or standard; TGSUD:

Internationally accepted test guideline or standard under development; SCI: Established as standard method in scientific literature; O: Other method and/or more research needed; N: No method identified. The method categories are ranked highest to lowest: TGSS, TGUD, SCI, O and N. Other abbreviations: TR: technical report; TS: technical report; GD: guidance document; Organisation for Economic Co-operation and Development (OECD); ISO: International Organization for Standardization; ECHA: the European Chemicals Agency; WNT: Working Group of the National Coordinators for the Test Guidelines Programme.

Highest method

\section{Waiving criteria}

category

(7.7) Hydrolytically stability or readily oxidisable*

(7.8) The substance is inorganic

(7.14bis) Exposure to granular form of the substance during its life-cycle can be excluded

(9.1.1; 9.1.2; 9.1.3; 9.1.4; 9.2.2.1; 9.2.1.2) The substance is highly insoluble in water**

(9.1.1; 9.1.2; 9.1.3; 9.1.4) The substance is unlikely/has low potential to cross

TGSUD

TGSUD

biological membranes

(9.2.2.1; 9.2.1.2; 9.1.4) The substance is readily biodegradable

(9.1.4) The applied test concentrations are in the range of concentrations that can be expected in the influent of a sewage treatment plant

(9.3.1) Based on physicochemical properties, the substance is expected to have a low potential for adsorption (e.g. the substance has a low octanol-water partition coefficient)

(9.3.2) The substance has low potential for bioaccumulation (for instance a log $\left.\mathrm{K}_{\mathrm{ow}} \leq 3\right)$

\section{Methods, protocols and guidance identified}

OECD WNT Project 3.10: TG under development. ${ }^{22}$

No method needed.

No method identified.

OECD WNT Project 3.10: TG under development ${ }^{22}$; OECD WNT Project 1.5: GD under development. ${ }^{22}$

Flow-cytometry, microscopy, ICP-MS and TEM for cellular uptake $^{61}$; In vitro assay(s) for cytotoxicity and cytokine induction $^{64,65}$; Biokinetics-oriented tests for capability of cell penetration. 66,67

OECD TG 301A-F. ${ }^{68}$

No method identified.

ECHA Guidance ${ }^{* * * 13,14}$; Dye staining to measure hydrophobicity. ${ }^{42}$

ICP-MS or AAS for analysis of NMs in dissolved tissue of aquatic

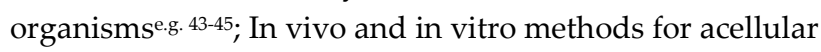
dissolution in physiological fluidse.g. 36; OECD WNT Project 3.12. GD under development. ${ }^{22}$ 
rapidly

(9.3.2) Direct and indirect exposure of the aquatic compartment is unlikely

$\mathrm{N}$

No method identified

(9.4) Direct and indirect exposure of the soil compartment is unlikely

No method identified

* Hydrolytically NMs are in this context considered unstable or readily oxidisable or rapidly dissolving (half-life less than $12 \mathrm{~h}$ ); ${ }^{* *}$ For nanoforms, the study may not be waived on the basis of high insolubility in water alone ${ }^{4 * * *}$ Information requirement only partially covered by ECHA Guidance.11

Table 4. Additional information requirements and the criteria for triggering the additional requirements for registration of nanoforms in REACH and category of identified highest-ranked methods needed to acquire/fulfill information requirements and associated criteria. TGS: Internationally accepted test guideline or standard; TGSUD: Internationally accepted test guideline or standard under development; SCI: Established as standard method in scientific literature; O: Other method and/or more research needed; N: No method identified. For further details, see Electronic Supplementary Material B. The method categories are ranked highest to lowest: TGS, TGSUD, SCI, O and N. Other abbreviations: TR: technical report; TS: technical report; GD: guidance document; Organisation for Economic Co-operation and Development (OECD); ISO: International Organization for Standardization; ECHA: the European Chemicals Agency; WNT: Working Group of the National Coordinators for the Test Guidelines Programme.

\begin{tabular}{ll}
\hline $\begin{array}{l}\text { Criteria for additional information } \\
\text { requirements }\end{array}$ & $\begin{array}{l}\text { Additional information } \\
\text { requirements }\end{array}$ \\
\hline $\begin{array}{l}\text { (7.7.) The substance appears "insoluble" in } \\
\text { water }\end{array}$ & \\
& $\begin{array}{l}\text { (7.7) Limit test up to the detection } \\
\text { limit of the analytical method shall } \\
\text { be performed. For nanoforms the } \\
\text { potential confounding effect of } \\
\text { dispersion shall be assessed when } \\
\\
\end{array}$
\end{tabular}

\section{Highest method} category

TGSUD

OECD WNT Project 1.5 and $3.10^{22}$. OECD GD $318^{23}$

OECD TG $318^{34}$ addresses dispersion stability of nanomaterials in simulated environmental media using multi-parameter matrix and analysis by DLS, ICP-MS/OES and AAS techniques. 
(9.1.1) The substance is poorly water soluble, or for nanoforms if they have low dissolution rate in the relevant test media.

9.1.1) The long-term aquatic toxicity study on Daphnia (Annex IX, section 9.1.5.) shall be

considered

(7.14ter) Indication that specific additional particle properties significantly influence the hazard of or the exposure to those nanoforms

(8.8.1) For nanoforms without high dissolution rate in biological media

(9.1.3) The chemical safety assessment according to Annex I indicates the need to investigate further effects on aquatic organisms.
8.8.1) A toxicokinetics study shall be proposed by the registrant or may be required by the Agency in accordance with Article 40
OECD WNT Project 3.10 TG under development ${ }^{22}$; OECD WNT Project 1.5: GD under development ${ }^{22}$; OECD GD 318.22

OECD TG 211: Daphnia magna Reproduction Test. ${ }^{69}$

Essential to determine the kinetics of changes in surface reactivity/composition, article stability/mobility in solution etc. Surface speciation and chemical speciation predication in solution is essential to asses. ${ }^{31}$

OECD WNT Project 3.10: TG under development ${ }^{22}$; OECD WNT Project 1.5: GD under development ${ }^{22}$; OECD GD 31823; ECHA Guidance R7.1a and R7.1b appendices* 13; OECD GD 2927: applicable for some NMs; Multiparameter matrix methodse.g. 29,35; Dissolution study of metal NMs environmental (freshwater) conditions. ${ }^{30,31}$ 
(9.1.3) Long-term aquatic toxicity testing as described in Annex IX

shall be considered.

(9.1.3) The substance is poorly water soluble, or for nanoforms if they have low dissolution rate in the relevant test media.

(9.1.3) The long-term aquatic toxicity study on fish (Annex IX, Section 9.1.6) shall be considered

(9.2) Nanoforms that are not soluble, nor have high dissolution rate

(9.2) Morphological transformation (e.g. irreversible changes in particle size, shape and surface properties, loss of coating)

(9.2) Chemical transformation (e.g. oxidation, reduction)

(9.2) Other abiotic degradation (e.g. photolysis)

(9.4) For substances that have a high potential

to adsorb to soil
OECD WNT Project 3.10: TG under development ${ }^{22}$; OECD WNT Project 1.5: GD under development ${ }^{22}$; OECD GD $318^{23}$

OECD TG $204^{70}$.

OECD WNT Project 3.10: TG under development ${ }^{22}$; OECD WNT Project 1.5: GD under development ${ }^{22}$; OECD GD $318^{23}$.

Band gap measured by UV-vis-NIR absorption measurements; probe force microscopy; soft X-ray methods. ${ }^{\text {e.g. }}{ }^{36}$; Redox potential measurements. e.g. 71,72

Combining TEM with energy-dispersive X-ray spectroscopy (EDX) for elemental composition of the nanoparticles ${ }^{61,73}$; Attenuated Total Reflection Fourier transform infrared Spectroscopy (ATRFTIR ${ }^{74 ;}$ Atomic force microscopy (AFM) - changes in particle morphology and size $\mathrm{e}^{\text {e.g. }}$.75; Zeta potential measurement ${ }^{76}$ and reporting ${ }^{77}$; X-ray Absorption Spectroscopy. ${ }^{78}$

Spectroscopic tools like FTIR ${ }^{74}$ and EXAFS ${ }^{79}$; OECD TG $312^{46}$ is applicable for NMs ${ }^{13,47,48,}$; Retention determination of silver and 
(9.4) The registrant shall consider

long- term toxicity testing instead of

short-term.

(9.4) For substances that are very persistent

9.4) The registrant shall consider

long- term toxicity testing instead of short-term. cerium oxide nanomaterials in soils. ${ }^{80}$; Draft OECD TG on

Agglomeration Behaviour of Nanomaterials in Different aquatic

Media. ${ }^{62}$

OECD TG $204 . .^{70}$
OECD WNT 3.16 project: GD under development. ${ }^{22}$

OECD TG $204 . .^{70}$

* Information requirement only partially covered by ECHA Guidance. ${ }^{11}$ 
According to our findings, almost $80 \%$ of the information requirements related to physico-chemical properties and environmental endpoints of NMs in the revised REACH Annexes are supported by methods that are established as internationally accepted TGs or standards $(15 \%)$, under development to be established as internationally accepted TGs or standards (25\%) or established in the scientific literature (40\%). Overall, ECHA guidance and OECD GDs are in place where TGs or standards are missing as presented in a recent overview of guidelines and other guidance. ${ }^{14}$ Key TGs and guidance include OECD TG $318^{34}$, OECD GD $317^{32}$ and $318^{23}$ and ECHA guidance released for NM substance identification and chemical safety assessment, especially the R7.1a and R7.1b appendices. ${ }^{13}$ These documents as well as the huge work efforts made to reach these important milestones are recognised as a significant advancement in the regulatory field of NMs.

Despite the progress made to develop nano-specific methods and guidance, the application of these to some NMs may still pose a number of challenges. For example, this is the case for the regulation information requirement 9.4 on effects on terrestrial organisms, for which ECHA notes that OECD GD $317^{32}$ may be updated to help registrants fulfill the requirement. ${ }^{14}$ While this awaits, it is stated that: "In the absence of toxicity data for soil organisms, the equilibrium partitioning method may be applied to assess the hazard to soil organisms.". ${ }^{4}$ However, the suitability and relevance of partitioning measures for NMs have been rejected in the scientific literature. ${ }^{81,82}$ This is also recognised in the regulation and it is clarified that where the equilibrium partitioning method is applied to nanoforms, this shall be scientifically justified. Based on the current scientific knowledge, it seems unlikely that it will be possible to provide such justification. The issue of applying partitioning measures to NMs also applies to the closely related information requirement: partition coefficient n-octanol/water. According to ECHA, ${ }^{14}$ methods to support this information requirement are partially covered in the ECHA Guidance on registration and chemicals safety assessment of nanomaterials. ${ }^{13}$ ECHA furthermore inform that "Dispersion stability to be considered when Kow is not applicable" and refer to TG 318: Dispersion Stability of Nanomaterials in Simulated Environmental Media. ${ }^{34}$ While this method partly covers interaction with natural organic matter it does not cover the functionality changes in relation to e.g. changes in hydrophobicity ${ }^{42}$ which would changes the nanoparticle fate in the environment. For rapidly soluble NMs the same approach would apply as for conventional chemicals. ${ }^{33}$ Instead, relevant information would be dissolution rate, according to the WPMN. ${ }^{17}$ However, for solubility (and dissolution rate) the methods are under development and NM registrants are in the meantime referred to the OECD GD 318. ${ }^{23}$ In Valsesia et al..$^{83}$ a method for quantifying surface hydrophobicity of NMs is proposed as an alternative method to octanol-water coefficient relevant information. Quantification is done by comparing NM binding affinity to specifically functionalised surfaces. Moreover, it should be highlighted that a work is ongoing in the OECD on a TG on determination of surface hydrophobicity of nanomaterials. This work is anticipated to be finalised in 2023 .

For the information requirements related to adsorption/desorption in aquatic environments, methods are only partially covered in guidance (i.e. ECHA guidance). Current methods relies mainly on partition coefficients and separation techniques such as filtration and centrifugation. When using such methods the cut-off threshold has to be considered in order to correctly interpret the results obtained. This can be challenging especially when considering unstable suspensions where the particle size changes as a function of time. In general, the methods presented are mainly applicable to highly soluble and/or small stable NMs. Adsorption as a function of interaction with naturally occurring substances should be considered, as they have been shown to alter e.g. hydrophobicity and thus the potential adsorption/desorption. ${ }^{42}$ Hydrophobicity of NMs in aquatic environments can be measured by use of e.g. dye staining. ${ }^{42}$ It has been proposed that OECD TG 312 Leaching in Soil Columns ${ }^{42}$ could provide for an alternative approach to the equilibrium partitioning method. ${ }^{13,47,48 \text {, }}$ For this method, a draft OECD GD for NMs is under development. ${ }^{14}$ OECD TG 303A on Particle 
Attachment and Removal from Wastewater ${ }^{49}$ can furthermore be used as an alternative approach to predict sorption of NMs.

It is very important to note that it is not always possible to establish univocally whether methods exist that would enable a registrant to meet a given information requirement. For instance, in some cases there might be methods for which TGs, standards or guidance exist that are only applicable to some forms of NMs. An example, the OECD GD 2927 is only applicable to metal NMs. For certain information requirements, the guidance referred to are only partially applicable to NMs. ECHA Guidance R7.1a and R7.1b appendices ${ }^{13}$ does for example only partially cover the information requirement '9.3.1 Adsorption/desorption'.

\subsection{Waiving criteria}

For the proper functioning of the regulation, it is crucial that the waiving criteria are clearly defined and supported by the necessary methods to justify their activation. Our analysis shows that for slightly more than $40 \%$ of the waiving criteria, methods are either available as internationally accepted TGs or standards (17\%), under development to be $(17 \%)$ or established in the scientific literature $(8 \%)$. But for a third of the waiving criteria, no specific methods are identified.

The majority of the waiving criteria for which no methods were identified, relates to criteria for certain exposure scenarios, i.e., if a certain exposure is unlikely to occur, the information requirement can be waived. This is the case if exposure of certain forms of the substance or the exposure to certain systems or environmental compartments are evaluated to be unlikely. Currently, no methods exist to fully document such evaluations. For environmental exposure, fate models such as SimpleBox4Nano, that predicts environmental concentrations of NMs in air, water, sediment and soil ${ }^{84,85}$ and Probabilistic material flow analysis ${ }^{86}$ may be informative..$^{87}$ Despite progressive development of such models, they cannot stand alone to justify "no exposure"/"low exposure". Such indications of "no exposure"/"low exposure" should be carefully evaluated case-by-case, before accepting any waiving of regulatory requirements. Lessons learned from previous cases show that though it may not be intended, substances used in society will inevitably be found in the environment at some point in time. ${ }^{88}$

Certain waiving criteria rely on the octanol-water coefficient, $K_{\text {ow }}$ and sets out that an information requirement can be waived e.g. if the $K_{\text {ow }}$ is low or under a certain value. As it is mentioned earlier for the information requirements based on partitioning methods, these principles are not deemed scientifically applicable to NMs. ${ }^{81,82}$ In contrast to the information requirement, no alternative guidance is provided on how to assess this endpoint.

For inorganic NMs the information requirement on Kow can be waived. Challenges may arise for substances that consist of both organic and inorganic materials, such as inorganic particles with organic coatings. Organic coatings are widely used to stabilise inorganic NPs, such as silver NPs. ${ }^{89}$ In addition to consider inorganic substances with organic coatings as one substances it might be viewed as a mixture of two substances. However, it is not clear from the regulation how these substances are to be classified. Furthermore, some organic NMs may act inorganically. E.g. carbon nanotubes, $\mathrm{C} 60$ and carbon black have been proven to show persistence despite their carbon-based structure. ${ }^{90}$

The ecotoxicological tests required by the regulation does not need to be conducted if there are mitigating factors indicating that aquatic toxicity (for tests on invertebrates, algae and fish) and microbial toxicity (for activated sludge respiration inhibition testing) are unlikely to occur. This is for instance the case if the substance of concern is "highly insoluble in water". A new nano-specific OECD TG for solubility and dissolution rate testing is currently under development. ${ }^{22}$ Whether this TG will actually address the traditional endpoint of solubility is not certain, as the focus is on the dissolution rate. According to Rasmussen et al.,33 dissolution and dissolution rate are considered more relevant parameters than solubility for particulate materials. The ecotoxicological tests together with the bioaccumulation test can also be waived if the substance of concern is/has "unlikely/low potential to cross biological membranes". No exact methods are currently available to address this endpoint, however studies are reported in the scientific literature. Cellular uptake can be studied using e.g. flow-cytometry, microscopy, ICP-MS and TEM for cellular uptake ${ }^{61}$ and in vitro assay(s) 
used to study cytotoxicity and cytokine induction may also be relevant.64,65 Lastly, biokineticsoriented tests can be used to indicate whether a given NM is capable of cell penetration. ${ }^{66,67}$ However, it is doubtful whether such approaches are enough to justify the potential activation of the waiving criteria.

If a substance is "readily biodegradable" a couple of the information requirements of the regulation can be waived. According to Baun et al., ${ }^{91}$ environmental biodegradability can be evaluated for carbonaceous materials via adaptation of the OECD biodegradation TGs series. ${ }^{68}$ Here, a material is considered readily biodegradable if $60 \% / 70 \%$ of the organic carbon in the material is converted to $\mathrm{CO}_{2} /$ removed-within 28 days of testing. Again, the question arises on how to classify e.g. inorganic NMs with organic coatings. Biodegradability evaluations are only considered relevant for carbon-based NMs, ${ }^{91}$ which points to a need to clarify which types of NMs this waiving criteria apply to.

In our view, the challenges identified here for justification of the activation of current waiving criteria in the revised REACH Annexes, ${ }^{4}$ may be overcome by introducing more clearly defined methodological advices, but it is not clear whether such activities have been initiated.

\subsection{Focus on development of methods to determine adsorption/desorption, exposure scenarios and ability} to cross biological membranes

While Cefic has called for waiving of data generation until standards and test methods are defined for information requirements where they are currently unavailable, ${ }^{12} \mathrm{ECHA}$ has taken the stance that the lack of certain test methods should not be a hurdle in the registration process. In our analysis, we found that methods are currently lacking for assessing adsorption/desorption in aquatic environments, exposure scenarios and ability to cross biological membranes. Based on this, we tend to agree with the ECHA viewpoint. ECHA relies heavily on the OECD and ISO test guidelines/guidances/standards in their guidance to industry on registration and chemicals safety assessment of NMs. While some methods have been standardised, e.g. ISO 19590 standard for NP size measurement in aqueous media by single particle ICP-MS, ${ }^{50}$ others are still under development, are lacking or are only applicable for some types of NMs. ${ }^{10}$ While it is tempting to call for waiving of data generation until test methods are standardised, it is important to remember that the process of standardisation and TG development can be very timely and that the development of new methods often require targeted research effort over decades of times. Development of internationally accepted TGs and standards may be fostered by the increasing reporting demands on e.g. characterisation information of NMs such as the ones put in place by ECHA. This creates a clear societal need for the development of standards and motivates the registrants to develop and share their own methods and ideas on data that they have generated on a given endpoint. These should, however, be followed up by funding of research and development into the specific information requirements for which, methods, protocols and standards are currently lacking, namely for evaluation of adsorption/desorption behavior in aquatic environments, exposure scenarios and ability of NM to cross biological membranes.

\subsection{Regulatory adequacy of methods - reliability and relevance}

Besides need of methods to support the information requirements or to justify waiving, it is important to recognise that methods that are valid from a scientific perspective may not be seen as adequate from a regulatory perspective..$^{92}$ The term "regulatory adequacy" traditionally involves an evaluation of the relevance and reliability of a method or a study for the regulatory question at hand. Data of high regulatory relevance and reliability is therefore data that are well-suited for specific decisionmaking processes e.g. risk assessment and management, 93,94 whereas "scientific relevance and reliability" is more open-ended and often curiosity driven. .5

In the field of nano-ecotoxicolgy the number of publications is rapidly increasing but the regulatory relevance and reliability of the reported findings has been questioned. ${ }^{96}$ Today a couple of methods exist for assessing the regulatory adequacy of (eco)toxicological data, among them the NanoCRED ${ }^{97}$ (available via the online tool SciRAP - Science in Risk Assessment and Policy www.scirap.org). NanoCRED is an adjusted version of the "Criteria for Reporting and Evaluating 
Ecotoxicity Data" (CRED) framework originally developed by Moermond et al. ${ }^{44}$ as an alternative to 471 the Klimisch method. The CRED framework is widely accepted for regulatory decision-making, e.g. 472 recommended for evaluation of ecotoxicity data when setting environmental quality standards under 473 the Water Framework Directive in the European Union..$^{98}$ We therefore suggest that more focus are 474 put on the NanoCRED reporting recommendations. If registrants were required to carry out 475 NanoCRED evaluations of their studies ECHA could publish these as part of the information on chemicals that they provide to enhance public access and transparency to the information. This will ensure that essential details are reported on when fulfilling the requirements of REACH Annexes but may also act as a guidance for registrants when performing studies.

\section{9}

480

481

482

483

484

485

486

487

488

489

490

491

492

493

494

495

496

497

498

499

500

501

502

503

504

505

506

507

508

509

510

511

512

513

\section{Conclusions and recommendations}

In this study, we assessed the degree of availability and suitability of methods needed to comply with the new technical data requirements to nanomaterials in the European Union's chemicals legislation for physico-chemical characterisation and environmental fate and effect assessment. In total, there are 20 additional, nano-specific information requirements for which methods are needed in order to register substances as nanoforms in REACH. For 15\% of the information requirements, we found that internationally accepted TGs or standards are available. For $25 \%$ of the information requirements, we identified methods that are under development but which are expected to be developed into internationally accepted TGs or standards. Finally, we find that for $40 \%$ of the information requirements, well-established methods are available through the scientific literature e.g. growth inhibition studies on aquatic plants and short-term toxicity testing on fish. Most of the relevant methods in the scientific literature are included in recent OECD GDs, ECHA guidance or ISO TRs and TS's. For four out of the 20 information requirements, we conclude that more research is needed to establish regulatory adequate methods. That is for methods related to quantification of adsorption/desorption, functional changes related to changes in e.g. hydrophobicity following exposure to aquatic environments and degradation. We also conclude that two of the 12 waiving criteria $(17 \%)$ are supported by internationally accepted TGs or standards and for another $17 \%$ of the methods by internationally accepted TGs or standards under development. For 4 out of 12 waiving criteria, no methods were identified to support whether the criteria can be waived or not. We recommend that a targeted effort is made to develop methods, protocols and guidelines for information requirements and waiving criteria, which currently lack such information. To help fulfill the regulation information requirement on effects on terrestrial organisms, OECD GD 317 on Aquatic and Sediment Toxicological Testing of Nanomaterials ${ }^{32}$ may be updated as noted by ECHA. We would, however, suggest that a GD on effects on terrestrial organisms is developed in parallel to the updates of OECD GD 317. It would further be helpful to clearly define and develop methodological advice on what it means for a NMs to be readily biodegradable, if the current information requirement are maintained. We also recommend that the development within the field of environmental exposure modelling of NMs should follow closely and be taken into account to help the registrants to justify "no exposure"/"low exposure" evaluations. We recommend that methods and/or guidance are developed to assess the waiving criteria of whether a NM is "likely to cross biological membranes". Certain information requirements and waiving criteria rely on partitioning methods, which are not deemed scientifically applicable to NMs. Instead of these, more relevant measures have been pointed to, e.g. dispersion stability ${ }^{14}$ and dissolution rate ${ }^{17}$, and here NMrelevant guidance is available/under development. Finally, we recommend that increasing attention be put on reporting on regulatory reliability and relevance of the information that is submitted by the registrants. Specifically, this could include the adoption of NanoCRED reporting requirement for ecotoxicity studies and that ECHA makes these scores available as part of the information on NMs that they provide to enhance public access to information.

\section{Conflicts of interest}

There are no conflicts to declare. 
The financial support from the research program Mistra Environmental Nanosafety Phase II, funded by the Swedish Foundation for Strategic Environmental Research (Mistra), and the PATROLS - Advanced Tools for NanoSafety Testing under Horizon 2020 research and innovation programme, is greatly acknowledged. Jonas Hedberg, from KTH Royal Institute of Technology Department Chemistry, is acknowledged for his help with identifying methods for information requirements and waiving criteria on physico-chemical properties and environmental fate and effects.

\section{References}

1. Markiewicz M, Kumirska J, Lynch I, Matzke M, Köser J, Bemowsky S, et al. Changing environments and biomolecule coronas: Consequences and challenges for the design of environmentally acceptable engineered nanoparticles. Green Chem. 2018;20(18):4133-68. Available from: DOI: 10.1039/c8gc01171k

2. Sørensen SN, Baun A, Burkard M, Dal Maso M, Foss Hansen S, Harrison S, et al. Evaluating environmental risk assessment models for nanomaterials according to requirements along the product innovation StageGate process. Environ Sci Nano. 2019;6(2):505-18. Available from: DOI: 10.1039/c8en00933c

3. Mattsson MO, Simkó M. The changing face of nanomaterials: Risk assessment challenges along the value chain. Regul Toxicol Pharmacol. 2017;84:105-15. Available from: http://dx.doi.org/10.1016/j.yrtph.2016.12.008 0273-2300/৫

4. COMMISSION REGULATION (EU) 2018/1881 of 3 December 2018 amending Regulation (EC) No 1907/2006 of the European Parliament and of the Council on the Registration, Evaluation, Authorisation and Restriction of Chemicals (REACH) as regards Annexes I, III,VI, VII, VIII, IX, X, XI, and XII to address nanoforms of substances. Available online: https://eur-lex.europa.eu/legalcontent/EN/TXT/PDF/?uri=CELEX:32018R1881\&from=en (accessed 20 January 2021)

5. REGULATION (EC) No 1907/2006 OF THE EUROPEAN PARLIAMENT AND OF THE COUNCIL of 18 December 2006 concerning the Registration, Evaluation, Authorisation and Restriction of Chemicals (REACH). Available online: https://eur-lex.europa.eu/legal-content/EN/TXT/?uri=CELEX\%3A02006R190720140410 (accessed 20 January 2021)

6. Appendix for nanoforms applicable to the Guidance on Registration and Substance Identification. European Chemicals Agency (ECHA). December 2017. Available online: https://echa.europa.eu/documents/10162/13655/how_to_register_nano_en.pdf/f8c046ec-f60b-4349-492be915fd9e3ca0 (accessed 21 October 2020).

7. ECHA delays guidance updates on REACH nano registrations. Chemical Watch. 17 June 2020. Available online: https://chemicalwatch.com/126581/echa-delays-guidance-updates-on-reach-nano-registrations (accessed 20 September 2020)

8. ECHA probing scant REACH nano registrations. Chemical Watch. 26 February, 2020. Available online: https://chemicalwatch.com/96249/echa-probing-scant-reach-nano-registrations (accessed 20 September 2020)

9. ECHA says only a sixth of substances containing nanoforms are registered. Chemical Watch. 6 August 2020. Available online: https://chemicalwatch.com/126581/echa-delays-guidance-updates-on-reach-nanoregistrations (accessed 20 September 2020)

10. Gao X, Lowry G V. Progress towards standardized and validated characterizations for measuring physicochemical properties of manufactured nanomaterials relevant to nano health and safety risks. NanoImpact [Internet]. 2018;9(September 2017):14-30. Available from: https://doi.org/10.1016/j.impact.2017.09.002

11. REACH Annexes amendments to address nanoforms of substances: Cefic's perspective. Cefic. Available online: https://cefic.org/app/uploads/2019/02/Nanomaterial-nanomaterials.pdf (accessed 21 October 2020).

12. Tougher action needed on REACH nano registrations - NGO. Chemical Watch. 20 May, 2020. Available online: https://chemicalwatch.com/118069/tougher-action-needed-on-reach-nano-registrations-ngo

13. Guidance on Information Requirements and Chemical Safety Assessment. Available online: https://echa.europa.eu/guidance-documents/guidance-on-information-requirements-and-chemical-safetyassessment (accessed 21 October 2020).

14. Overview of REACH information requirements and available methods. European Union Observatory for Nanomaterials (EUON). Available online: https://euon.echa.europa.eu/reach-test-methods-fornanomaterials (accessed 9 October 2020). 
15. Experts call for updated guidance on nanomaterial risk assessment. Chemical Watch. 26 March 2020. Available online: https://chemicalwatch.com/103033/experts-call-for-updated-guidance-on-nanomaterialrisk-assessment (accessed 9 October 2020).

16. Schwirn K, Voelker D, Galert W, Quik J, Tietjen L. Environmental Risk Assessment of Nanomaterials in the Light of New Obligations Under the REACH Regulation: Which Challenges Remain and How to Approach Them? Integr Environ Assess Manag. 2020;16(5):706-17. Available from: 10.1002/ieam.4267

17. Rasmussen K, Rauscher H, Kearns P, González M, Riego Sintes J. Developing OECD test guidelines for regulatory testing of nanomaterials to ensure mutual acceptance of test data. Regul Toxicol Pharmacol [Internet]. 2019;104(February):74-83. Available from: https://doi.org/10.1016/j.yrtph.2019.02.008

18. Who develops standards? International Organization for Standardization (ISO). Available online: https://www.iso.org/who-develops-standards.html (accessed 25 January 2021)

19. Deliverables. International Organization for Standardization (ISO). Available online: https://www.iso.org/deliverables-all.html (accessed 25 January 2021)

20. Faria M, Björnmalm M, Thurecht KJ, Kent SJ, Parton RG, Kavallaris M, et al. Minimum information reporting in bio-nano experimental literature. Nat Nanotechnol [Internet]. 2018;13(9):777-85. Available from: http://dx.doi.org/10.1038/s41565-018-0246-4

21. Chetwynd AJ, Wheeler KE, Lynch I. Best practice in reporting corona studies: Minimum information about Nanomaterial Biocorona Experiments (MINBE). Nano Today [Internet]. 2019;28:100758. Available from: https://doi.org/10.1016/j.nantod.2019.06.004

22. Work plan for the Test Guidelines Programme (TGP). OECD. June 2019. Available online: https://www.oecd.org/env/ehs/testing/ENV_JM_WRPR_2019_TGP-work-plan.pdf (accessed 22 October 2020)

23. OECD Guidance Document for the Testing of Dissolution and Dispersion Stability of Nanomaterials, and the Use of the Data for Further Environmental Testing and Assessment. Series on Testing and Assessment No. $318.20 \quad$ July $2020 . \quad$ Available online: http://www.oecd.org/officialdocuments/publicdisplaydocumentpdf/?cote=env/jm/mono(2020)9\&doclang uage=en (accessed 22 January 2021)

24. Koltermann-jülly J, Keller JG, Vennemann A, Werle K, Müller P, Ma-hock L, et al. Addendum to “ Abiotic dissolution rates of 24 ( nano ) forms of 6 substances compared to macrophage-assisted dissolution and in vivo pulmonary clearance: Grouping by biodissolution and transformation " [NanoImpact 12. NanoImpact [Internet]. 2019;14(March):100154. Available from: https://doi.org/10.1016/j.impact.2019.100154

25. OECD Test No. 105: Water Solubility. 27 July 1995. Available online: https://www.oecdilibrary.org/docserver/9789264069589en.pdf?expires=1611317892\&id=id\&accname=guest\&checksum=A614A97E4F3493186FC920A73B935675 (accessed 22 January 2021)

26. ISO/TR 19057:2017 Nanotechnologies - Use and application of acellular in vitro tests and methodologies to assess nanomaterial biodurability. October 2017. Available online: https://www.iso.org/standard/63836.html (accessed 22 January 2021)

27. OECD Series on Testing and Assessment, No. 29. Guidance Document on Transformation/Dissolution of Metals and Metal Compounds in Aqueous Media. 23 July 2001. Available online: http://www.oecd.org/officialdocuments/publicdisplaydocumentpdf/?cote=env/jm/mono(2001)9\&doclang $\underline{\text { uage }=\text { en }}$ (accessed 22 January 2021)

28. Wasmuth C, Rüdel H, Düring RA, Klawonn T. Assessing the suitability of the OECD 29 guidance document to investigate the transformation and dissolution of silver nanoparticles in aqueous media. Chemosphere. 2019;28:100785. Available from: https://doi.org/10.1016/j.chemosphere.2015.10.101

29. Xiao Y, Vijver MG, Peijnenburg WJGM. Impact of water chemistry on the behavior and fate of copper nanoparticles. Environ Pollut [Internet]. 2018;234:684-91. Available from: https://doi.org/10.1016/j.envpol.2017.12.015

30. Pradhan S, Hedberg J, Rosenqvist J, Jonsson CM, Wold S, Blomberg E, Wallinder IO. Influence of humic acid and dihydroxy benzoic acid on the agglomeration, adsorption, sedimentation and dissolution of copper , manganese , aluminum and silica nanoparticles - A tentative exposure scenario. PLOS one., 2018;1-24. Available from: https://doi.org/10.1371/journal.pone.0192553 February 
31. Hedberg J, Blomberg E, Wallinder IO. In the Search for Nanospecific Effects of Dissolution of Metallic Nanoparticles at Freshwater-Like Conditions: A Critical Review. Environ. Sci. Technol., 2019; 53, 4030-4044. Available from: https://doi.org/10.1021/acs.est.8b05012

32. OECD Guidance Document on Aquatic and Sediment Toxicological Testing of Nanomaterials. Series on Testing and Assessment No. 317. 20 July 2020. Available online: https://www.oecd.org/officialdocuments/publicdisplaydocumentpdf/?cote=env/jm/mono(2020)8\&doclan guage=en (accessed 22 January 2021)

33. Rasmussen K, Rauscher H, Mech A, Riego Sintes J, Gilliland D, González M, et al. Physico-chemical properties of manufactured nanomaterials - Characterisation and relevant methods. An outlook based on the OECD Testing Programme. Regul Toxicol Pharmacol [Internet]. 2018;92(October 2017):8-28. Available from: https://doi.org/10.1016/j.yrtph.2017.10.019

34. OECD Test No. 318: Dispersion Stability of Nanomaterials in Simulated Environmental Media. 9 October 2018. Available online: https:/www.oecd-ilibrary.org/docserver/9789264284142en.pdf?expires=1611320272\&id=id\&accname=guest\&checksum=49D1213ADE156A574FC615EEA3A49556 (accessed 22 January 2021)

35. Von Der Kammer F, Ottofuelling S, Hofmann T. Assessment of the physico-chemical behavior of titanium dioxide nanoparticles in aquatic environments using multi-dimensional parameter testing. Environmental Pollut [Internet]. 2010;158(12):3472-81. Available from: http://dx.doi.org/10.1016/j.envpol.2010.05.007

36. Steinhäuser KG, Sayre PG. Reliability of methods and data for regulatory assessment of nanomaterial risks. NanoImpact [Internet]. 2017;7(June):66-74. Available from: https://doi.org/10.1016/j.impact.2017.06.001

37. EN 15051-1. Workplace exposure - Measurement of the dustiness of bulk materials - Part 1: Requirements and choice of test methods. 1 November $2013 . \quad$ Available online: https://standards.globalspec.com/std/1648937/en-15051-1 (accessed 22 January 2021)

38. EN 15051-2. Workplace exposure - Measurement of the dustiness of bulk materials - Part 2: Rotating drum method. 15 May 2014. Available online: https://standards.iteh.ai/catalog/standards/sist/7e210dac-5ecb4044-829b-7bd8c8f73e06/sist-en-15051-2-2014 (accessed 2 January 2021)

39. EN 15051-3. Workplace exposure - Measurement of the dustiness of bulk materials - Part 3: Continuous drop method. 27 November $3013 . \quad$ Available online: https://standards.iteh.ai/catalog/standards/cen/bcd7038c-9bec-4569-94c1-2d46ca9496f6/en-15051-3-2013 (accessed 22 January 2021)

40. ISO/TS 20787:2017 Nanotechnologies - Aquatic toxicity assessment of manufactured nanomaterials in saltwater lakes using Artemia sp. Nauplii. November 2017. Available online: https://www.iso.org/standard/69087.html (accessed 22 January 2021)

41. ISO/TR 11360:2010 Nanotechnologies - Methodology for the classification and categorization of nanomaterials. July 2010. Available online: https://www.iso.org/standard/55967.html (accessed 22 January 2021)

42. Crandon, L. E., Boenisch, K. M., Harper, B. J. \& Harper, S. L. Adaptive methodology to determine hydrophobicity of nanomaterials in situ. PLoS One. 2020;15, 1-17. Available from: http://dx.doi.org/10.1371/journal.pone.0233844

43. Gray EP, Coleman JG, Bednar AJ, Kennedy AJ, Ranville JF, Higgins CP. Extraction and analysis of silver and gold nanoparticles from biological tissues using single particle inductively coupled plasma mass spectrometry. Environ Sci Technol. 2013;47(24):14315-23. Available from: dx.doi.org/10.1021/es403558c

44. Hedberg J, Ekvall MT, Hansson L. Tungsten carbide nanoparticles in simulated surface water with natural organic matter: dissolution, agglomeration, sedimentation and interaction with Daphnia magna. Environ. Sci.:. 2017;4, 886-94. Available from: https://doi.org/10.1039/c6en00645k

45. Ekvall MT, Hedberg J, Wallinder IO, Cedervall T, Ekvall MT, Hedberg J, et al. Long-term effects of tungsten carbide (WC) nanoparticles in pelagic and benthic aquatic ecosystems. Nanotoxicology [Internet]. 2018;12:79-89. Available from: https://doi.org/10.1080/17435390.2017.1421274

46. OECD Test No. 312: Leaching in Soil Columns. 13 April 2004. Available online: https://www.oecdilibrary.org/docserver/9789264070561en.pdf?expires $=1611321227 \&$ id $=$ id\&accname= guest\&checksum $=$ A386F3BFCD7BB201EAF65A8EF539A645 (accessed 22 January 2021)

47. Kühnel D, Nickel C. The OECD expert meeting on ecotoxicology and environmental fate - Towards the development of improved OECD guidelines for the testing of nanomaterials. Sci Total Environ [Internet]. 2014;472:347-53. Available from: http://dx.doi.org/10.1016/j.scitotenv.2013.11.055 
48. Nickel C, Gabsch S, Hellack B, Nogowski A, Babick F, Stintz M, et al. Mobility of coated and uncoated TiO 
66. Sayre PG, Steinhäuser KG, van Teunenbroek T. Methods and data for regulatory risk assessment of nanomaterials: Questions for an expert consultation. NanoImpact [Internet]. 2017;8(June):20-7. Available from: https://doi.org/10.1016/j.impact.2017.07.001

67. Zhu, M., Nie, G., Meng, H., Xia, T., Nel, A. \& Zhao, Y. Physicochemical Properties Determine Nanomaterial Cellular Uptake, Transport, and Fate. Acc. Chem. Res. 2013;46(3), 622-631. Available from: https://doi.org/10.1021/ar300031y

68. OECD TG 301 Series A-F. Ready Biodegradability. 17 July 1992. Available online: https://doi.org/10.1787/9789264070349-en

69. OECD Test No. 211: Daphnia magna Reproduction Test. 2 October 2012 . Available online:https://doi.org/10.1787/9789264185203-en (accessed 22 January 2021)

70. OECD Test No. 204: Fish, Prolonged Toxicity Test: 14-Day Study. 4 April 1984. https://doi.org/10.1787/9789264069985-en (accessed 22 January 20219)

71. Zhou, Y.-G., Rees, N. V. \& Compton, R. G. The electrochemical detection and characterization of silver nanoparticles in aqueous solution. Angewandte Chemie (International ed. in English) 2011, 50, 4219-4221. Available from: DOI: 10.1002/anie.201100885

72. Hedberg YS, Pradhan S, Cappellini F, Karlsson ME, Blomberg E, Karlsson HL, et al. Electrochemical surface oxide characteristics of metal nanoparticles $(\mathrm{Mn}, \mathrm{Cu}$ and $\mathrm{Al}$ ) and the relation to toxicity. Electrochim Acta [Internet]. 2016;212:360-71. Available from: http://dx.doi.org/10.1016/j.electacta.2016.07.017

73. Kettiger H, Schipanski A, Wick P. Engineered nanomaterial uptake and tissue distribution: from cell to organism. International Journal of Nanomedicine. 2013;3255-69. Available from: https://doi.org/10.2147/IJN.S49770

74. Mudunkotuwa IA, Minshid A Al, Grassian VH. ATR-FTIR spectroscopy as a tool to probe surface adsorption on nanoparticles at the liquid-solid interface in environmentally and biologically relevant media. Analyst. 2014;139(5):870-81. Available from: https://doi.org/10.1039/c3an01684f

75. Kent RD, Vikesland PJ. Dissolution and Persistence of Copper-Based Nanomaterials in Undersaturated Solutions with Respect to Cupric Solid Phases. Environ. Sci. Technol. 2016, 50, 6772-6781. Available from: https://doi.org/10.1021/acs.est.5b04719

76. Lowry G V., Hill RJ, Harper S, Rawle AF, Hendren CO, Klaessig F, et al. Guidance to improve the scientific value of zeta-potential measurements in nanoEHS. Environ Sci Nano. 2016;3(5):953-65. Available from: https://doi.org/10.1039/c6en00136j

77. Skoglund S, Hedberg J, Yunda E, Godymchuk A, Blomberg E, Odnevall Wallinder I. Difficulties and flaws in performing accurate determinations of zeta potentials of metal nanoparticles in complex solutions - Four case studies. PLoS One. 2017;12(7):1-19. Available from: https://doi.org/10.1371/journal.pone.0181735

78. López-Moreno, ML, de la Rosa, G., Hernández-Viezcas, JA., Peralta-Videa, JR., \& Gardea-Torresdey, JL. Xray Absorption Spectroscopy (XAS) Corroboration of the Uptake and Storage of CeO 2 Nanoparticles and Assessment of Their Differential Toxicity in Four Edible Plant Species. J. Agric. Food Chem. 2010, 58, 36893693. Available from: https://doi.org/10.1021/jf904472e

79. Mitsunobu, S., Takahashi, Y., Utsunomiya, S., Marcus MA., Terada, Y., Iwamura, T. \& Sakata, M. Identifcation and characterization of nanosized tripuhyite in soil near $\mathrm{Sb}$ mine tailings. American Mineralogist, 2011, 96, 1171-1181. Available from: https://doi.org/10.2138/am.2011.3651

80. Cornelis G, Kirby EJK, Beak BD, C DDC, A MJM. A method for determination of retention of silver and cerium oxide manufactured nanoparticles in soils. 2010, 7, 298-308. Available from: doi:10.1071/EN10013

81. Praetorius A, Tufenkji N, Goss KU, Scheringer M, Von Der Kammer F, Elimelech M. The road to nowhere: Equilibrium partition coefficients for nanoparticles. Environ Sci Nano. 2014;1(4):317-23. Available from: https://doi.org/10.1039/c4en00043a

82. Arvidsson R, Baun A, Furberg A, Hansen SF, Molander S. Proxy Measures for Simplified Environmental Assessment of Manufactured Nanomaterials. Environ Sci Technol. 2018;52(23):13670-80. Available from: https://doi.org/10.1021/acs.est.8b05405

83. Valsesia A, Desmet C, Ojea-Jiménez I, Oddo A, Capomaccio R, Rossi F, et al. Direct quantification of nanoparticle surface hydrophobicity. Commun Chem. 2018;1(1). Available from: DOI: 10.1038/s42004-0180054-7

84. Meesters JAJ, Koelmans AA, Quik JTK, Hendriks AJ, Van De Meent D. Multimedia modeling of engineered nanoparticles with simpleBox4nano: Model definition and evaluation. Environ Sci Technol. 2014;48(10):5726-36. Available from: https://doi.org/10.1021/es500548h 
85. Simplebox4nano. National Institute for Public Health and the Environment Ministry of Health, Welfare and Sport, Nederlands. RIVM. 9 July 2017. Available online: https://www.rivm.nl/en/soil-andwater/simplebox4nano (accessed 15 October 2020)

86. Gottschalk F, Scholz RW, Nowack B. Probabilistic material flow modeling for assessing the environmental exposure to compounds: Methodology and an application to engineered nano-TiO2 particles. Environ Model Softw [Internet]. 2010;25(3):320-32. Available from: http://dx.doi.org/10.1016/j.envsoft.2009.08.011

87. Nowack B. NanoImpact Evaluation of environmental exposure models for engineered nanomaterials in a regulatory context. NanoImpact [Internet]. 2017;8(June):38-47. Available from: https://doi.org/10.1016/j.impact.2017.06.005

88. Foss Hansen S, Maynard A, Baun A, Tickner JA. Late lessons from early warnings for nanotechnology. Nat Nanotechnol. 2008;3(8):444-7. Available from: https://doi.org/10.1038/nnano.2008.198

89. Sharma VK, Siskova KM, Zboril R, Gardea-Torresdey JL. Organic-coated silver nanoparticles in biological and environmental conditions: Fate, stability and toxicity. Adv Colloid Interface Sci [Internet]. 2014;204:1534. Available from: http://dx.doi.org/10.1016/j.cis.2013.12.002

90. Hartmann, N.B., Skjolding, L.M., Hansen, S.F., Kjølholt, J., Gottschalck, F. \& Baun, A. Environmental fate and behaviour of nanomaterials - new knowledge on important transformation processes. In: Environmental Project no. 1594. 2014. Danish Environmental Protection Agency, Copenhagen, Denmark. Available from: file://C:/Users/mabini/Desktop/Legal\%20Analyzes/Regulations/Analysis\%20Annex\%20rev\%20\%20methods\%20available/References/Hartmann\%20et\%20al.\%202014.pdf

91. Baun A, Sayre P, Steinhäuser KG, Rose J. Regulatory relevant and reliable methods and data for determining the environmental fate of manufactured nanomaterials. NanoImpact [Internet]. 2017;8(June):1-10. Available from: https://doi.org/10.1016/j.impact.2017.06.004

92. Guidance on information requirements and chemical safety assessment Chapter R.4: Evaluation of available information Version 1.1. European Chemicals Agency (ECHA). December 2011. Available online: https://echa.europa.eu/documents/10162/13643/information_requirements_r4_en.pdf/d6395ad2-15964708-ba86-0136686d205e (accessed 22 January 2021)

93. Hjorth R, Skjolding LM, Sørensen SN, Baun A. NanoImpact Regulatory adequacy of aquatic ecotoxicity testing of nanomaterials. NanoImpact [Internet]. 2017;8(July):28-37. Available from: https://doi.org/10.1016/j.impact.2017.07.003

94. Moermond CTA, Kase R, Korkaric M, Ågerstrand M. CRED: Criteria for reporting and evaluating ecotoxicity data. Environ Toxicol Chem. 2016;35(5):1297-309. Available from: https://doi.org/10.1002/etc.3259

95. Nature Nanotechnology. A different view of the environment. Nat. Nanotech. 13, 177 (2018). Published: 06 March 2018. Available online: https://www.nature.com/articles/s41565-018-0106-2\#article-info (accessed 18 September 2020).

96. Skjolding LM, Sørensen SN, Hartmann NB, Hjorth R, Hansen SF, Baun A. A Critical Review of Aquatic Ecotoxicity Testing of Nanoparticles - The Quest for Disclosing Nanoparticle Effects Aquatic Ecotoxicity Testing of Nanoparticles - The Quest To Disclose Nanoparticle Effects. Angew. Chem. Int. Ed. 2016, 55, 2 - 18. Available from: DOI: 10.1002/anie.201604964.

97. Hartmann NB, Ågerstrand M, Lützhøft HH, Baun A. NanoImpact NanoCRED : A transparent framework to assess the regulatory adequacy of ecotoxicity data for nanomaterials - Relevance and reliability revisited. NanoImpact- 2017, 6, 81-89. Available from: https://doi.org/10.1016/j.impact.2017.03.004

98. Technical Guidance For Deriving Environmental Quality Standards. Guidance Document No: 27. European Commission. 2018. Available online: https://rvs.rivm.nl/sites/default/files/201904/Guidance\%20No\%2027\%20-\%20Deriving\%20Environmental\%20Quality\%20Standards\%20\%20version\%202018.pdf (accessed 22 January 2021) 